\title{
改善高密度城市区域通风的城市形态优化策略研究 以香港新界大埔墟为例
}

\author{
Urban Ventilation Strategies for Micro Climate Improvement in Subtropical High-density Cities: \\ A Case Study of Tai Po Market in Hong Kong
}

郑颖生 史源 任超 吴恩融

Zheng Yingsheng, Shi Yuan, Ren Chao, NG Edward

\begin{abstract}
摘要: 高速的城市化进程, 改变了城市的地表材质和空间结构, 引发城市气候的改变。我国众多城市呈现升温趋势, 夏季高温问题尤为严峻。研 究证实, 促进区域通风是改善亚热带高温高湿夏季条件下人体舒适度的最有效方法之一。基于改善城市夏季气候条件并保障城市环境健康的目的, 本文选取香港新界大埔墟地区为例, 探讨如何通过促进夏季通风, 改善区域微气候条件, 为亚热带高密度城市的可持续规划以及区域城市更新提 供思路参考。首先, 根据建筑平均高度及覆盖率, 在大埔墟地区研究范围内划分多层高密度区、高层中密度区, 以及开阔区三个区域类型, 进行 行人层高度的风环境分析; 然后, 基于上述分析, 探讨如何通过城市用地置换、街区形态及建筑形态改造等策略改善区域通风条件, 以达到缓解 夏季高温的目的; 最后, 选取城市更新前后的经济技术指标、天空视域因子（SVF: Sky View Factor）以及行人层高度的风速（通过流体动力学模 拟获得) 三种类型参量进行量化比较, 验证在高密度建设的前提下, 通过优化城市形态达到改善区域夏季通风的可行性。

Abstract: The process of urbanization has changed the surface properties and spatial structures of urban areas, and accordingly, induced urban climate change. A warming trend has been observed in many cities of China, associated with severe heat events in summer. Previous studies have found that improving air ventilation in one of the most effective methods to enhance thermal comfort under the hot and humid summer of subtropical cities. Aiming at improving urban microclimate and enhancing human thermal comfort, this paper develops urban regeneration strategies based on the case study of Tai Po Market in Hong Kong. Firstly, the three zones of Tai Po Market: compact mid-rise zone, open high-rise zone and sparsely built zone are defined and analyzed in the aspects of urban morphology and microclimate. Secondly, land use change, traffic reorganization and building transformation are recommended for solving the existing air ventilation problems in Tai Po Market. Finally, Economic and technical indexes, Sky View Factor, and wind speed at pedestrian level (based on computational fluid dynamics simulation results) are compared to verify the possibility of wind environment improvement through urban morphology optimization under the same density.
\end{abstract}

关键词：高密度区域；通风；高温高湿夏季；形态优化；量化评估；流体动力学模拟

Keywords: High-density Areas; Ventilation; Hot and Humid Summer; Morphological Optimization; Quantitative Evaluation; CFD Simulation

香港研究资助局研究项目“局地气候区划系统在高密度城市的应用——香港为例” (RGC-ECS458413)

作者: 郑颖生 (通信作者), 香港中文大学建筑学院, 博士研究生。zhengyingsheng@gmail.com

史源, 香港中文大学建筑学院, 博士研究生。shiyuan.arch.cuhk@gmail.com

任超, 香港中文大学建筑学院, 助理教授, 香港中文大学环境、能源及可持续发展研究研究员。renchao@cuhk.edu.hk

吴恩融, 香港中文大学建筑学院, 教授, 香港中文大学环境、能源及可持续发展研究所管理委员会委员、研究员。edwardng@cuhk.edu.hk 


\section{1 背景}

\section{1 研究的缘起一一夏季高温问题}

人类活动对地表形态以及大气构成的改变, 引发全球气 候变暖。气象数据表明, 1983-2012 年, 是全球近 1400 年 以来最热的 30 年 ${ }^{[1]}$ 。我国正处于高速城市化的时期, 城市 的表面材质、空间结构迅速改变, 并由此产生了显著的热岛 效应。在全球范围气候变化以及城市热岛效应的双重作用下, 国内大部分城市自 1960-2003 年气温一致呈上升趋势 ${ }^{[2]}$ 。热 岛效应虽然在一定程度上缓解了寒冷地区冬季采暖的能源负 荷, 但也使我国大部分城市面临更加严峻的夏季气候环境问 题。北京、上海、杭州、广州等大型城市增温趋势加剧, 夏 季最高温度不断提高, 高温持续时间不断增加。气候环境与 公众健康密不可分, 酷热的夏季气候条件会对人体健康造成 威胁, 如容易引发肌肉痉挛、中暑、脱水等生理问题, 亦 导致神经活动机能下降, 心脑血管、肝炎发病率的增加 ${ }^{[3-5]}$ 。 城市建设引发的一系列气候环境与人体健康问题不容忽视， 其中一个重要原因是我们疏忽了城市建设与城市气候的相互 作用, 因此有必要整合城市气候学的研究成果并将其应用于 指导城市规划与建设。

\section{2 气候研究在香港规划建筑领域的应用探索}

城市建设显著改变城市气候, 而城市规划与设计是城市 建设的依据, 因此, 建立气候研究与规划研究领域的跨学科 交流平台, 将气候语言 “翻译”成规划设计语言, 促进城市 气候学研究成果在城市规划与设计领域更直接高效的应用, 是应对当今气候环境问题的重要策略。

为改善城市气候状况, 香港在 2003 年启动了城市空气 流通评估的研究, 并将研究成果收人《香港城市规划标准与 准则》第十一节《城市设计指引》 ${ }^{[6]}$ 。该准则从街区及地块 两个层面, 在街区、街道, 绿地布局, 建筑群体形态设计等 多方面提出了详细的指引。继而于 2006 年开展了第二期相 关研究《香港城市环境气候图及其风环境评估标准》 ${ }^{[7]}$, 以 城市气候图形式——“城市气候分析图”、“城市气候规划建 议图” ${ }^{[8]}$ 直观地反映区域气候条件并展示规划发展建议。此 外, 基于城市空气流通评估的研究成果，香港特别行政区 屋宇署于 2011 年颁布了改善地块通风的建筑设计导则《优 化建筑设计缔造可持续建筑环境》 ${ }^{[9]}$ 及 《可持续建筑设计指 引》 ${ }^{[10]}$, 对建筑设计各项指标提供量化建议。

\section{3 促进区域通风，改善香港高温高湿夏季的人体舒适度}

促进通风是缓解城市区域高温最有效方法之一 ${ }^{[11-13]}$ : 加 强城市区域通风, 令郊外的新鲜冷空气流人城市中心, 能够 缓解市区高温以及改善空气质量 ${ }^{[14]}$ 。同时, 风速是影响人体
舒适度的重要参数之一, 保障夏季室外环境的合理风速, 有 助于促进汗液蒸发带走热量, 提高人体舒适度 ${ }^{[15,16]}$ 。根据香 港天文台所录的气象数据可知, 香港的夏季高温潮湿, 同时 风速却是全年最低。研究表明, 在香港夏季的高湿度环境下, 风速提升 $0.7 \mathrm{~m} / \mathrm{s}$ (由 $0.3 \mathrm{~m} / \mathrm{s}$ 提高至 $1 \mathrm{~m} / \mathrm{s}$ ) 等效于气温降低 $2^{\circ} \mathrm{C}$ 所带来的热舒适感受 ${ }^{[17-19]}$ 。因此, 在夏季高温高湿的状 况下改善香港室外环境的人体舒适度, 通风显得尤为重要。

高密度建筑集群, 增加了城市表面粗粘度, 削弱了风在 城市空间内的流动, 尤其削弱了城市底部行人层的通风效率。 根据风的流体动力学特征, 如果高密度城区的开敞空间具备 合理的朝向、足够的尺度以及连续性, 仍能够实现有效通风。 香港城市空气流通评估的研究论证了通过合理规划, 满足高 建设密度的同时实现有效城市通风的可能性, 并建议通过优 化街道朝向、街区形态、建筑群体布局、绿地分布等具体方 式建立城市风道, 促进区域通风。

\section{2 促进夏季通风的形态优化策略一以新界大埔 墟为例}

\section{1 研究思路}

\subsection{1 研究背景}

香港是中国东南部沿海城市, 属于亚热带季风气候类型。 春秋冬三季气候温和, 但夏季平均气温达 $28^{\circ} \mathrm{C}$, 相对湿度 维持在 $80 \%$ 左右, 潮湿炎热的夏季气候导致人体舒适度不佳。 另一方面, 香港地少人多, 可建设用地范围内人口密度高达 2.5 万人 $/ \mathrm{km}^{2}$, 迫使香港通过高密度建设的方式缓解高密度 人口的居住生活需求 ${ }^{[20]}$ 。香港由香港岛、九龙、新界以及离 岛四大区域构成。其中, 香港岛与九龙半岛等城市中心区域 以高层高密度形态著称, 由于发展时间较早, 建设密度及土 地开发程度高, 尽管部分地区正在或将进行城市更新, 但总 体开发容量仍然有限。

新界地区则是香港全境最大的区域, 占地 $747 \mathrm{~km}^{2}$, 占 香港陆地总面积接近 70\%。新界地区土地开发程度相比于香 港岛与九龙半岛城区较低, 具备了较大的新市镇建设与城市 区域更新的潜力。目前, 香港特区政府正在积极开展新界东 北新发展区的专项研究, 增加土地供应, 以缓解城市中心区 的建设压力。人口统计数据亦表明：自 1996-2006 年的 10 年中, 新界部分城区人口快速增加, 城市人口呈现由传统城 市中心区向新界地区流动的趋势 ${ }^{[21]}$ 。在新界地区, 高层建筑 与多层低层建筑并存, 不同密度混合是普遍的建设形态。本 文研究区域大埔墟（图 1) 是反映新界城市建设状态的典型 案例: 一方面, 早期建设的低层及多层住宅, 普遍存在设施 陈旧, 缺乏公共空间, 以及建筑不合理布局导致环境质量不 良等多种问题; 另一方面, 近期建设的大量高层住宅区，临 
近早期多层低层住宅区, 在建筑形态、市政设施与环境质量 等方面存在鲜明对比。因此, 针对新旧建筑并存的复杂形态, 如何统筹考虑区域的建筑功能与空间布局, 改造旧区建筑形 态, 提升环境质量是大埔墟以及新界地区发展面临的主要挑 战。当前, 我国内地大中城市传统街区的改造更新也面临与 大埔墟相似的问题, 大埔墟环境改善方案对我国相似城区建 设改造有参考价值。

\subsection{2 研究方法}

本文首先运用流体动力学模拟软件模拟大埔墟夏季通风 状况, 发现通风状况不良的问题区域。其次, 以《香港城市 规划标准与准则》 ${ }^{[6]}$ 及 《可持续建筑设计指引|》 ${ }^{[10]}$ 中的定性、 定量导则作为设计依据, 遵循不降低原有建设密度及保证原 有功能结构的原则改进大埔墟区域形态, 针对问题区域提出 促进区域通风的城市形态更新策略, 以达到环境质量提升与 土地利用强度的平衡。同时运用地理信息系统 (ArcGIS) 以 及计算机辅助设计软件 (AutoCAD) 处理形态数据, 并将数 据结果可视化, 便于规划设计人员直观理解大埔墟改造前后 的城市形态变化。最后, 通过经济技术指标的统计数据比较 改造前后的区域建设状况, 并通过流体动力学模拟的风速数 据比较改造前后的通风状况, 以此量化说明区域形态改造对
大埔墟通风状况的提升作用。

\section{2 促进夏季通风的城市形态改进策略}

大埔墟北临林村河, 东临吐露港, 中部大埔河南北贯通, 拥有较丰富的临河及临海界面, 区域自然环境条件优越。目 前, 区域内新建的高层住宅与早期建设的多层住宅并存, 拥 有高低错落的城市形态, 塑造了复杂多样的微气候条件。根 据建筑高度和建筑覆盖率, 大埔墟地区划分为高层建筑为主 的中密度区域、多层建筑为主 (多层高层建筑混合) 的高密 度区域以及开阔区域三个分区（图 2, 表 1)。

大埔墟夏季盛行风为东风, 由区域东侧的吐露港海面 吹向陆地。本文运用流体动力学软件 (Computational Fluid Dynamics Software) 对大埔墟区域, 距地面 $1.5 \mathrm{~m}$ 高度的行 人层通风状况进行了模拟 (图 3)。从模拟结果可以看出 : 大

\section{表 1 大埔墟分区经济技术指标}

\begin{tabular}{lccc}
\hline & 多层高密度区域 & 高层中密度区域 & 开阔区域 \\
\hline 建筑平均高度 $(\mathrm{m})$ & 24.8 & 40.2 & 16.97 \\
建筑覆盖率 $(\%)$ & 55 & 29 & 4 \\
总建筑面积 $\left(\right.$ 万 $\mathrm{m}^{2}$ ) & 81.9 & 67.1 & 15.51 \\
建筑用地面积 $\left(\right.$ 万 $\mathrm{m}^{2}$ ) & 19.9 & 17.8 & 41.55 \\
容积率 & 5.4 & 3.8 & 0.37 \\
\hline
\end{tabular}

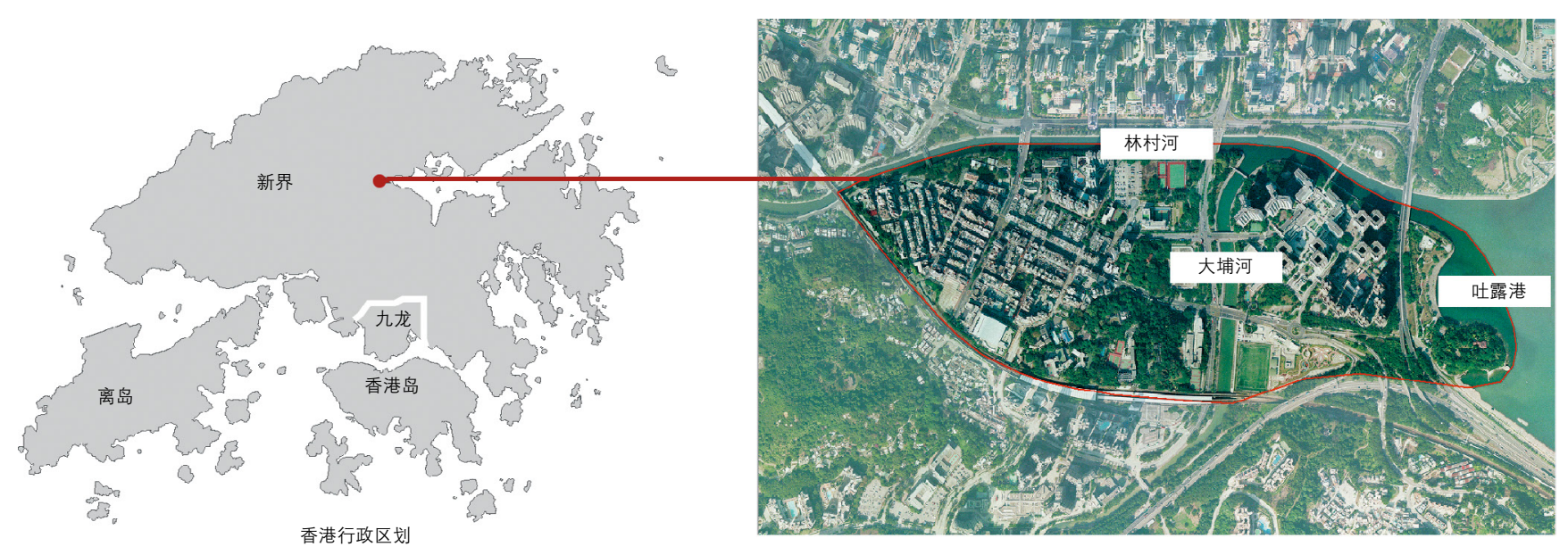

图 1 大埔墟区位

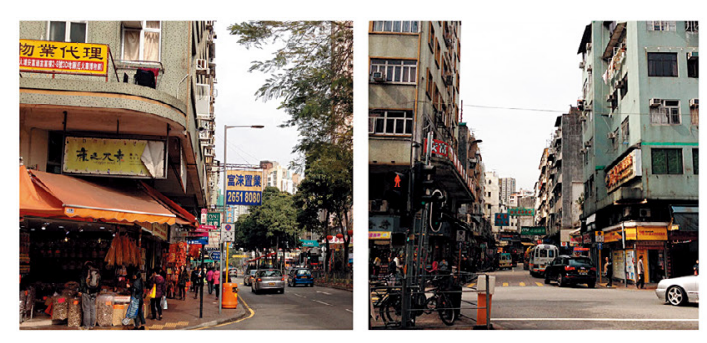

多层高密度区域

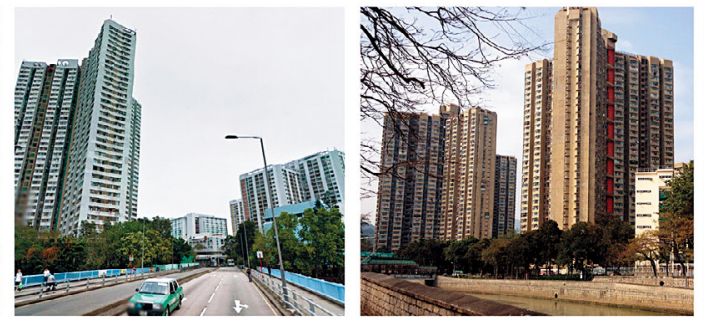

高层中密度区域

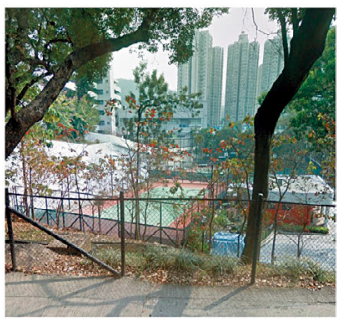

开阔区域

图 2 大埔墟建筑形态分区 
埔墟西侧的多层高密度区域, 建筑覆盖率高, 布局紧密, 街 道空间处于风速低于 $1 \mathrm{~m} / \mathrm{s}$ 的弱风状态, 甚至低于 $0.5 \mathrm{~m} / \mathrm{s}$ 的 静风状态, 是大埔墟通风效率提升的重点改进区域。大埔墟 北侧及东侧的高层中密度区域, 高层建筑群体对其下风向区 域通风产生较为显著的阻碍, 但高层建筑风影区落在由道路、 河道及绿地构成的开敞区域, 因此一定程度缓解了高层中密 度区域对其下风向多层高密度区域的挡风效应。基于流体动 力学模拟结果以及上述对区域形态特征及通风状况的分析, 本文总结大埔墟形态改进策略如下。

\subsection{1 功能置换}

多层高密度区域建筑覆盖率高, 紧密布局的唐楼占据大
量底层城市空间, 导致空气流通阻滞。关于香港高密度区域空 气流通的研究表明, 降低建筑覆盖率有利于提高城市底部空间 的通风效率 ${ }^{[1]}$ 。因此, 本文采用功能置换的方法, 对多层高密 度区域和高层中密度区域两个分区之间进行建筑功能置换, 在 保障大埔墟现有功能构成和建设密度前提下降低建筑覆盖率。 具体策略为：(1) 区域之间的功能置换 : 拆除多层高密度区域 的部分唐楼, 在高层中密度区域新建高层住宅楼, 维持拆除与 新建的住宅面积平衡。(2) 区域内部的功能置换 : 改造高层中 密度区域的高层建筑裙房形态, 适当增加裙房层数, 降低裙房 的占地面积。总结来说, 对于不同区域之间以及区域内部进行 功能置换, 降低大埔墟的总体建筑覆盖率, 加大城市空间的坚 向开发, 能够达到提高城市底部空间通风效率的目的（图 4)。

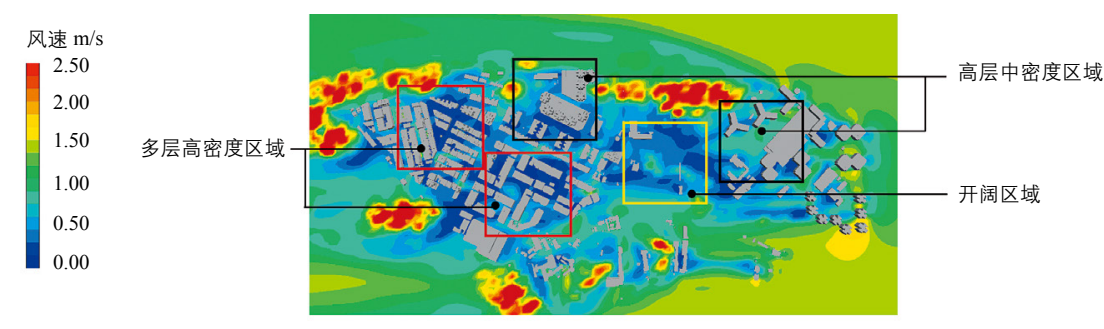

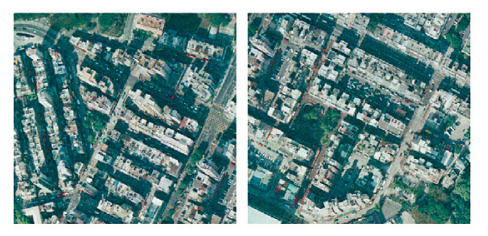

多层高密度区域

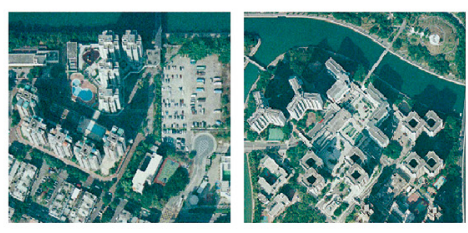

高层中密度区域

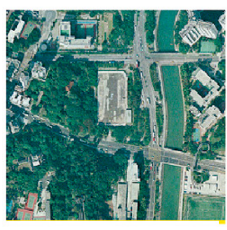

开阔区域

图 3 区域通风问题总结
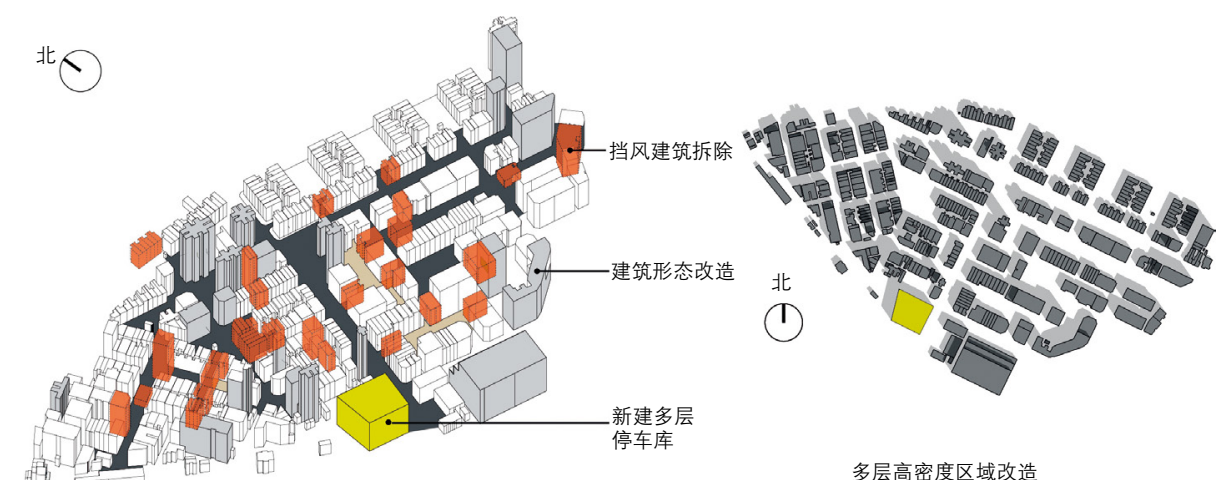

多层高密度区域改造

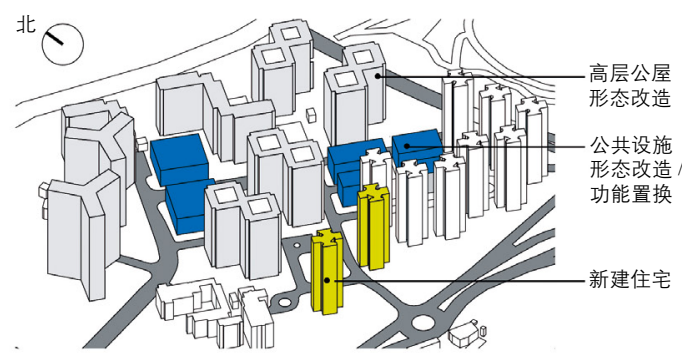

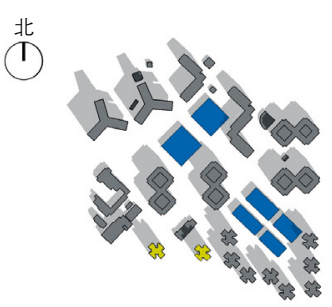

高层中密度区域改造

图 4 用地功能置换 


\subsection{2 街区空间形态调整}

在多层高密度区域中, 建筑沿街联排紧密布局, 形成了 规整的峡谷状的街道空间以及方正的广场空间。有限的街道 空间与广场空间是多层高密度区域空气流通的主要通道。街 道通风网络的部分节点存在挡风建筑, 广场周边建筑布局过 于紧密, 是引发多层高密度区域通风不良的主要原因。

根据屋宇署颁布的《可持续建筑设计指引》 ${ }^{[10]}$ 中的量化 设计导则, 调整街区形态及建筑群体布局。多层高密度区域 中, 拆除部分建筑, 将原有狭长型街区改造为多个小尺度街 区（图 5), 增大街道密度, 并控制连续街道界面的长度不超 过街区宽度的 5 倍 ${ }^{[10]}$, 增加城市空间在夏季盛行风向上的开 敞程度。同时, 减小街区的夏季盛行风迎风面宽度, 降低建 筑群体对通风的阻碍, 促进区域空气流通。

\subsection{3 建筑形态改造}

高层中密度区域的高层裙楼形态是影响该区域底部通风 状况的主要因素, 高层塔楼形态则是影响其下风向区域通风状 况的主要因素。改造中通过削减裙楼在夏季盛行风迎风面的面
宽, 以提升高层建筑底部的通风效率。塔楼形态改造方面, 《可 持续建筑设计指引》 ${ }^{[10]}$ 将高层塔楼坚向分为不同区域 : 低区 (0 $20 \mathrm{~m})$ 、中区 $(20 \sim 60 \mathrm{~m})$ 及高区 $(60 \mathrm{~m}$ 以上)。位于高区、 中区的建筑贯通空间, 能够加强高层建筑立面透风度, 削弱 高层塔楼对其下风向区域的挡风效应（图 6)。位于低区的建 筑贯通空间, 有助于人行高度处的空气流通。因此对高层中 密度区域内迎风体量较大的双塔型、 $\mathrm{Y}$ 型、 $\mathrm{L}$ 型公屋进行形 态改造，在坚向上设置低区、中区贯通空间，以提高高层住 宅的底部人行区域及其下风向开阔区域的通风效率（图 7)。

\section{3 参数比较及流体动力学模拟验证}

\subsection{1 经济技术指标}

基于香港高密度建设的现实发展需求, 区域改造应遵循 维持现有的城市形态与建设密度的前提。本研究采用的策略 是 : 对于多层高密度区域, 拆除内通风问题严峻地块内的挡 风建筑, 降低该地块建筑覆盖率, 提升该区域的整体通风状 况。在高层中密度区域内, 一方面新建高层住宅, 对多层高 密度区域拆除的住宅进行等面积置换 ; 另一方面, 改造高层
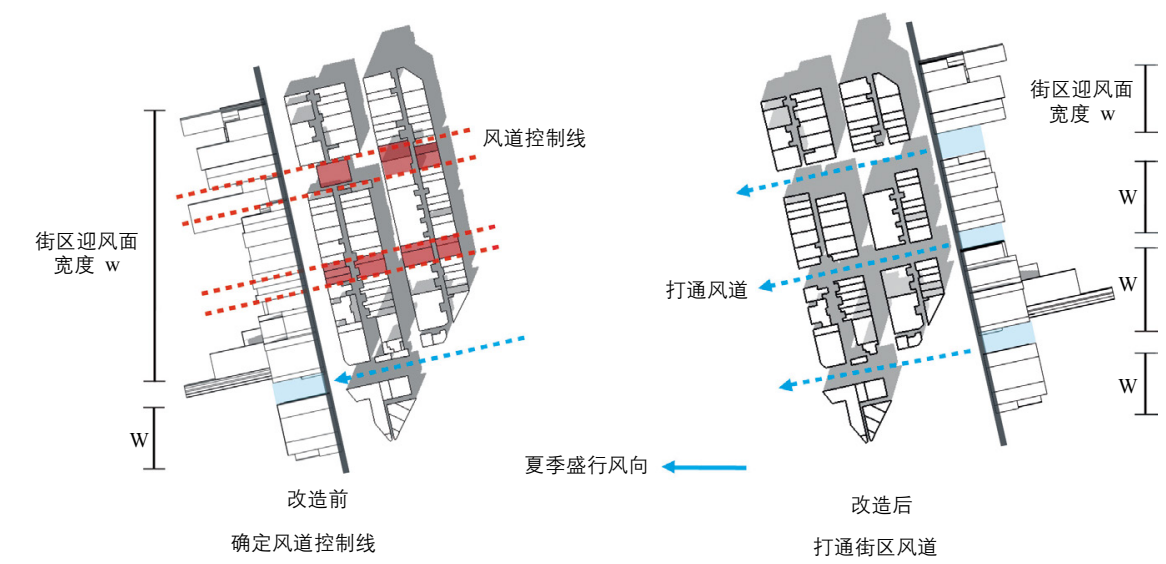

图 5 狭长型街区改造模式

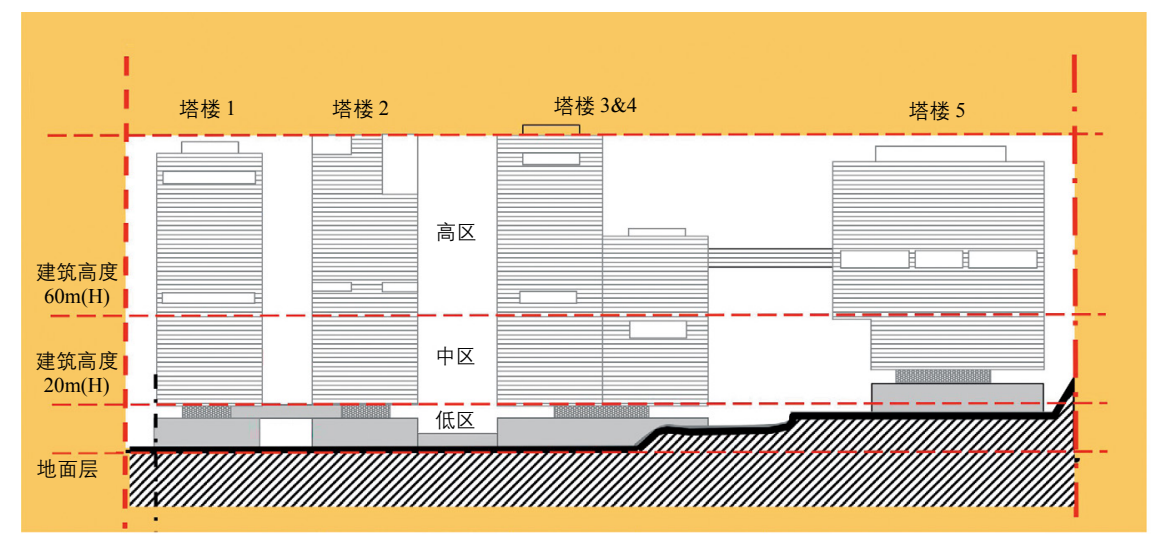

图 6 改善城市通风的高层建筑立面设计原则

资料来源 : 参考文献 [12] 
建筑底部的大型裙房形态, 削减体量, 并在开阔位置新建市 政设施进行面积补偿。从改造前后的经济技术指标比较上看, 多层高密度区域建筑覆盖率降低了 $7 \%$, 容积率降低了 0.5 , 总建筑面积减少了 6.4 万 $\mathrm{m}^{2}$; 高层中密度区域通过新建住宅 以及改造裙房形态, 总建筑面积增加了 6.4 万 $\mathrm{m}^{2}$, 实现了大 埔墟改造前后总建筑面积平衡。该区域虽然容积率上升了 0.3 , 建筑覆盖率仍降低了 $4 \%$, 加强了空间的坚向开发, 降 低了建筑物对城市底部行人层空间的影响（表 2)。

\subsection{2 区域形态比较}

除经济技术指标之外，本文引人“天空视域因子”这一 城市气候学参数进行改造前后城市形态评估。天空视域因子 (SVF: Sky View Factor) 是给定观察点的可见天空的比例 ${ }^{[22]}$ (观察点通常位于开放空间的地面), 是一个取值为 $0 \sim 1$ 的 无量纲参数。研究表明, SVF 与城市区域的通风效率、气温 以及热岛效应强度存在显著的线性相关关系 ${ }^{[23]}$ 。SVF 值越 低则观察点周边环境的封闭程度越高（即相应的建设密度越 高), 通风潜力以及释放多余热量的能力越低 ${ }^{[24]}$ 。另一方面, SVF 数值决定于观察点周围建筑布局方式、建筑高度、间距 等参量, 是一个反映城市建设密度的重要参数。因此, 天空 视域因子是一个既能量化评估城市形态又可预测区域通风潜 力、热工环境的综合指标。

\section{表 2 区域改造前后经济技术指标比较}

\begin{tabular}{l|c|c|c|c|c|c}
\hline \multirow{2}{*}{} & \multicolumn{3}{|c|}{ 多层高密度区域 } & \multicolumn{3}{|c}{ 高层中密度区域 } \\
\cline { 2 - 8 } & 改造前 & 改造后 & $\begin{array}{l}\text { 改造前 } \\
\text { 后差值 }\end{array}$ & 改造前 & 改造后 & $\begin{array}{c}\text { 改造前 } \\
\text { 后差值 }\end{array}$ \\
\hline 区域总面积 $\left(\right.$ 万 $\left.\mathrm{m}^{2}\right)$ & \multicolumn{2}{|c|}{19.9} & - & \multicolumn{2}{|c}{17.8} & - \\
\hline 道路覆盖率 $(\%)$ & \multicolumn{2}{|c|}{24} & - & \multicolumn{2}{|c}{10} & - \\
\hline 不透水表面覆盖率 $(\%)$ & 94 & 90 & -4 & 75 & 73 & -2 \\
\hline 透水表面覆盖率 $(\%)$ & 6 & 10 & +4 & 25 & 27 & +2 \\
\hline 建筑用地面积 $\left(\right.$ 万 $\left.\mathrm{m}^{2}\right)$ & \multicolumn{2}{|c|}{15.1} & - & \multicolumn{2}{|c|}{17.8} & - \\
\hline 建筑占地面积 $\left(\right.$ 万 $\left.\mathrm{m}^{2}\right)$ & 8.3 & 7.3 & -1 & 5.2 & 4.5 & -0.7 \\
\hline 建筑覆盖率 $(\%)$ & 55 & 48 & -7 & 29 & 25 & -4 \\
\hline 建筑平均高度 $(\mathrm{m})$ & 24.8 & 25.8 & +1 & 40.2 & 45.6 & +5.4 \\
\hline 总建筑面积 $\left(\right.$ 万 $\left.\mathrm{m}^{2}\right)$ & 81.9 & 74.5 & -6.4 & 67.1 & 73.5 & +6.4 \\
\hline 容积率 & 5.4 & 4.9 & -0.5 & 3.8 & 4.1 & +0.3 \\
\hline
\end{tabular}

\section{表 3 改造前后各观察点 SVF 数值统计}

\begin{tabular}{c|c|c|c|c}
\hline \multicolumn{2}{c|}{} & \multicolumn{3}{|c}{ 天空视域因子 } \\
\cline { 3 - 5 } \multicolumn{2}{c|}{} & 改造前 & 改造后 & 改造百分比 \\
\hline \multirow{4}{*}{ 多层高密度区域 } & 观察点 1 & 0.25 & 0.29 & $+16 \%$ \\
\cline { 2 - 5 } & 观察点 2 & 0.27 & 0.37 & $+37 \%$ \\
\cline { 2 - 5 } & 观察点 3 & 0.31 & 0.33 & $+7 \%$ \\
\hline \multirow{3}{*}{ 高层中密度区域 } & 观察点 4 & 0.22 & 0.33 & $+50 \%$ \\
\cline { 2 - 5 } & 观察点 5 & 0.36 & 0.46 & $+28 \%$ \\
\cline { 2 - 5 } & 观察点 6 & 0.42 & 0.32 & $-24 \%$ \\
\hline
\end{tabular}

选取多层高密度区域的观察点 P1、P2、P3 以及高层中 密度区域观察点 P4、P5、P6（图 8）进行改造前后的形态分 析及 SVF 数值比较 (图 9, 表 3)。通过拆除关键节点的挡风 建筑, 多层高密度区域的观察点 P1、P2 和 P3 的 SVF 数值增加,
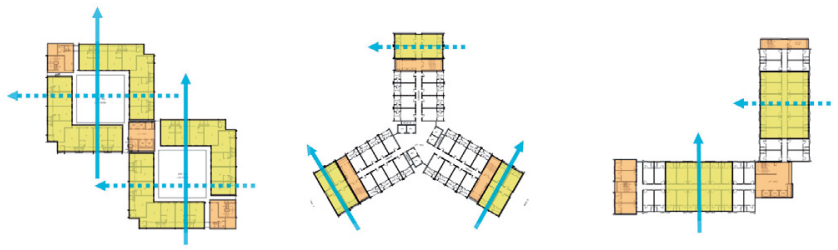

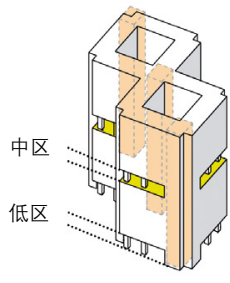

双塔型

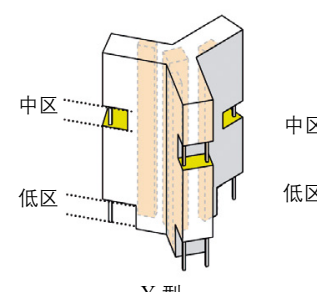

$\mathrm{Y}$ 型

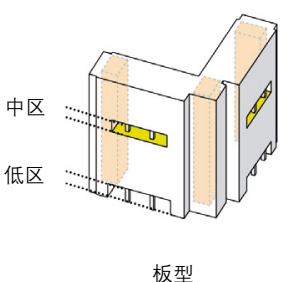

$\square$ 交通辅助空间
—夏季盛行风向 $4 \cdots$ 其他风向

图 7 高层公屋住宅形态改造模式

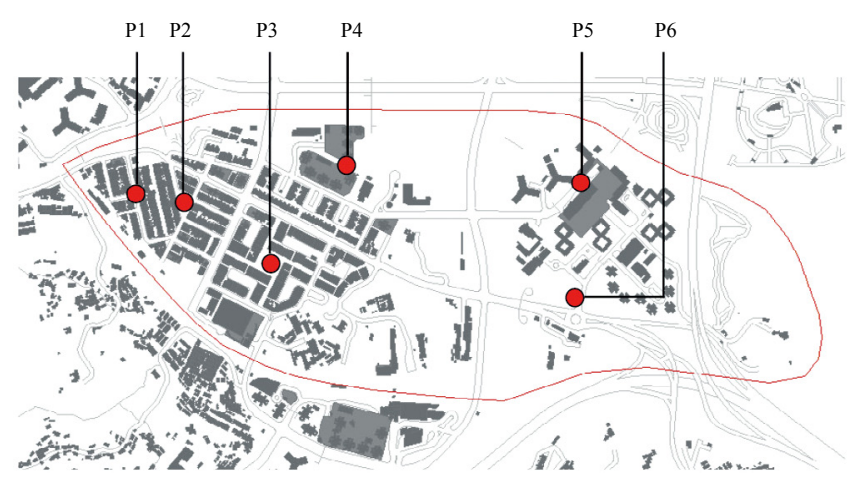

图 8 观察点位置
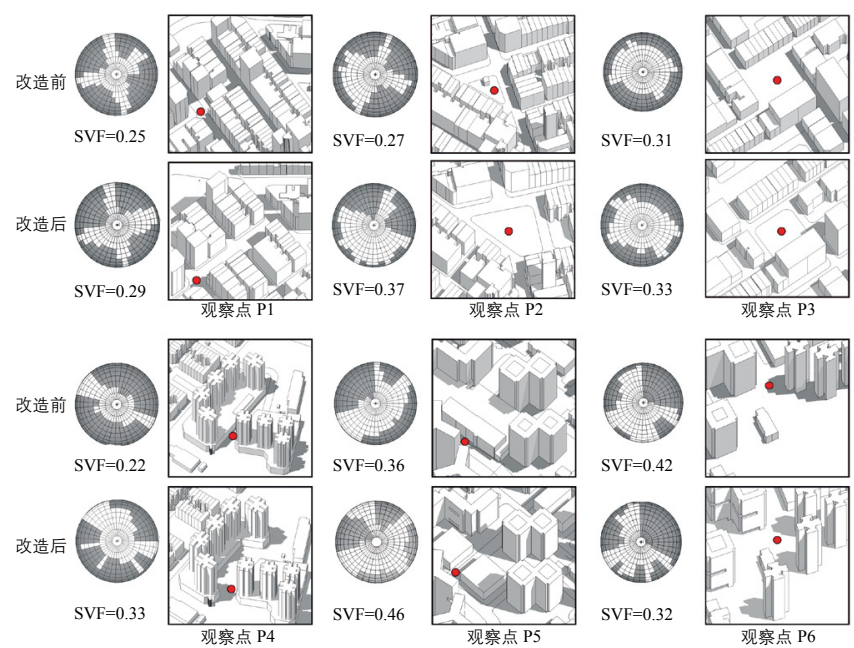

图 9 改造前后各观察点 SVF 数值与形态比较 
即观察点周边环境的开放程度提高。高层中密度区域内, 削 减 P4 及 P5 观察点处的裙房体量, 扩展 $20 \mathrm{~m}$ 宽的东西向通 风道, 使观察点 SVF 数值升高; 另一方面, 加建一层裙房 并在开阔区新建市镇设施补偿削减的建筑面积。观察点 P6 处, 由于其北侧新建高层住宅楼的影响, SVF 数值降低。从 整体角度看, 大埔墟地区总体 SVF 数值增加, 局部 SVF 数 值降低。在维持区域总建筑面积平衡的情况下, 城市坚向空 间利用增加, 城市环境的开敞程度提高。

\subsection{3区域夏季通风状况的模拟验证}

流体动力学模拟软件运用于模拟大埔墟地区改造前后的 风环境状况。从改造前后的模拟结果看出 (图 10), 改造后 多层高密度区域以及高层中密度区域通风均有明显改善, 建设 区域内静风风场（风速 0 $0.5 \mathrm{~m} / \mathrm{s}$ ）及弱风风场（风速 $0.5 \sim 1 \mathrm{~m} / \mathrm{s}$ ）
的覆盖范围显著减小。同时, 建设区域周边的红色强湍流风 场也相较于改造前有所减弱。P1 至 P5 观察点通过拆除挡风 建筑、重塑街道空间、改造建筑形态等方式打通区域的 “通 风道”, 使得通风状况均有明显提升。虽然 P6 观察点周边新 建高层住宅和加建公共设施使建设密度增加, 但 P6 位于大 埔墟上风向区域并且周边风道畅通，同时受到高层建筑周边 加速型风场的作用, P6 观察点风速相较于改造前反而有所 升高。

由综合改造前后的天空视域因子及风速状况（图 11）可 以看出, 改造之后总体 SVF 数值增加, 风速值提高, 即城 市形态开放程度提高, 区域透风程度增加。改造前后经济技 术指标、观察点的 SVF 数值及风速值三者的量化比较, 共 同验证了在保证大埔墟原有容积率的条件下, 通过优化城市 形态来提升区域通风状况、改善微观气候的可行性。

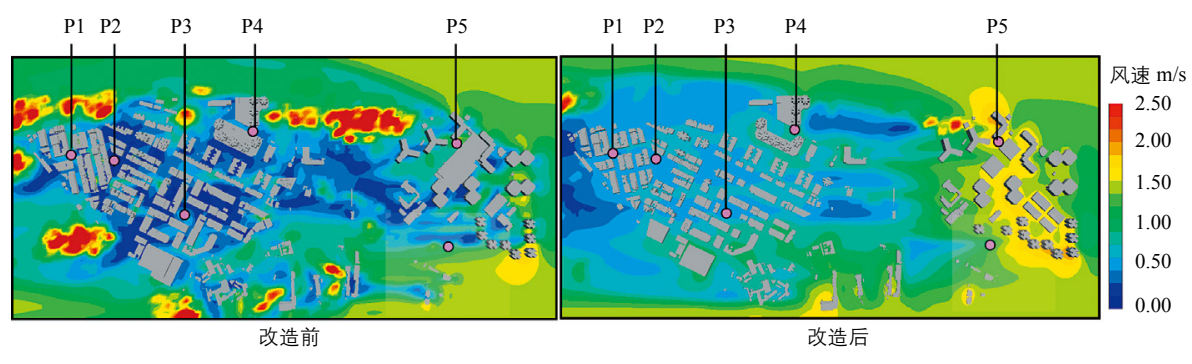

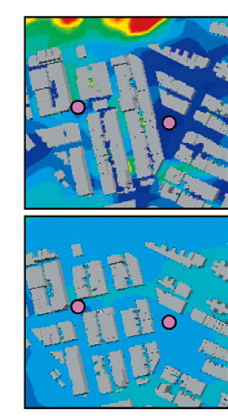

观察点 $\mathrm{P} 1$ 及 $\mathrm{P} 2$

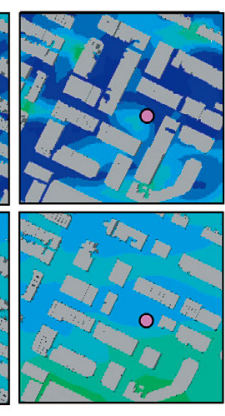

观察点 $\mathrm{P} 3$

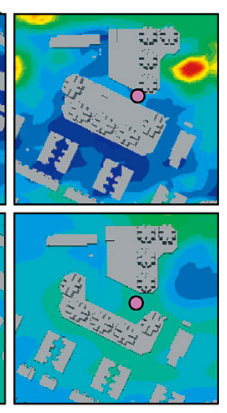

观察点 P4

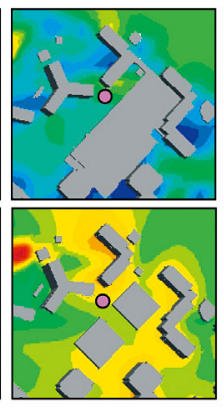

观察点 P5

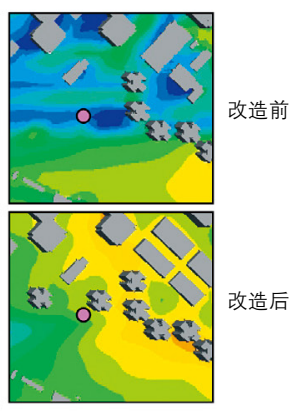

观察点 P6

图 10 改造前后通风状况模拟
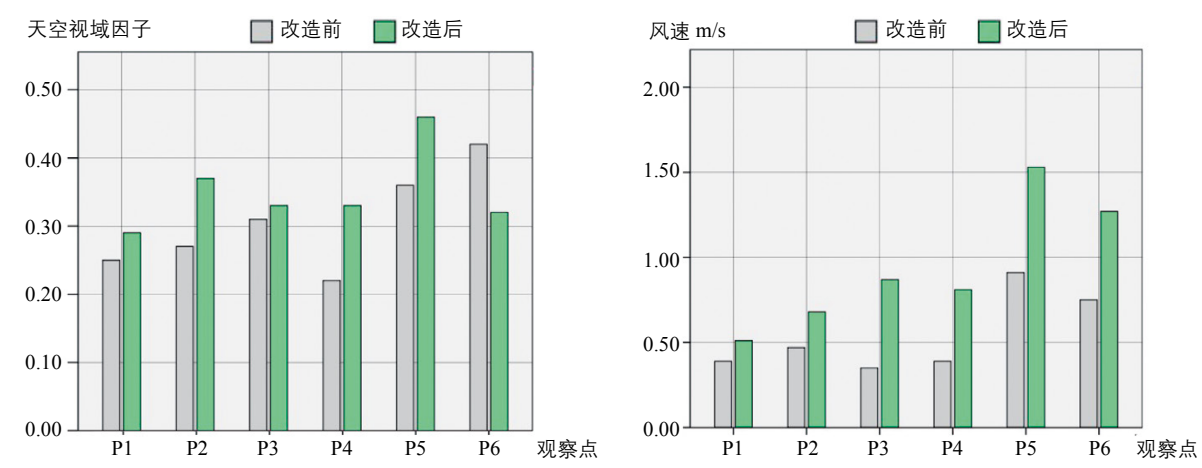

图 11 改造前后天空视域因子与风速的数值变化 


\section{3 结语}

在城市化进程中, 由于人口增长的压力以及土地资源的 限制，通过高密度的土地利用与城市空间的坚向开发来提高 城市空间利用率, 是城市发展的必然趋势。然而, 高密度的 城市建设改变了城市表面形态, 导致热岛效应加剧, 城市底 部空间采光不足，通风受阻等一系列环境问题，并对民众健 康造成影响 ${ }^{[25]}$ 。如何通过合理规划与建设, 寻求城市发展与 环境可持续的平衡成为广泛关注的焦点。

在规划设计方面, 需要将城市形态与城市环境的考量贯 穿于设计的各个阶段, 以实现城市发展与环境健康的平衡 :

（1）场地调研阶段评估环境现状, 结合经验判断、计算机 模拟以及场地实测等方法, 发现环境现状问题; (2) 方案阶 段根据场地调研成果, 通过计算机模拟手段, 量化评估规划 设计方案对环境的影响；（3）决策阶段综合评估各项经济技 术指标以及环境参量, 权衡社会经济各方要素, 选择综合最 优方案。在上述各阶段中, 规划设计领域与环境气候领域的 知识整合, 计算机模拟软件的应用, 以及形态数据与环境数 据的可视化, 是实现通过优化形态改善环境的关键之处。

本文以香港新界大埔墟地区为研究对象, 针对该区域新 旧建筑的共存, 不同密度的混合的现状, 利用流体动力学软 件对该地区夏季通风状况进行模拟, 针对通风不畅的部分区 域提出城市形态的改进方案, 并选取城市设计前后的技术经 济指标和风环境参数进行比较, 验证了在保障区域高建设密 度不变的前提下, 通过形态优化, 即减低建筑覆盖率、提高 建筑高度及透风度, 从而改善区域行人层通风的可行性, 为 我国亚热带高密度城市的气候优化设计提供参考。UP

\section{注：文中未注明来源的图表均为作者绘制}

\section{参考文献}

[1] Intergovernmental Panel on Climate Change. Climate Change 2013: The Physical Science Basis[R/OL]. [2013-11]. http://www.climatechange2013. org/images/report/WG1AR5_ALL_FINAL.pdf.

[2] 杜春丽. 我国城市气候变化特征及水汽图像的分析 [D]. 南京：南京信 息工程大学, 2008 .

[3] 付雪婷, 薛静, 王青, 等. 城市热岛效应与健康 [J]. 国外医学: 医学地 理分册, 2004, 25(1): 43-45.

[4] Tan J, Zheng Y, Tang X, et al. The Urban Heat Island and Its Impact on Heat Waves and Human Health in Shanghai[J]. International Journal of Biometeorology, 2010, 54(1): 75-84.

[5] Goggins W B, Chan E Y Y, Ng E, et al. Effect Modification of the Association Between Short-term Meteorological Factors and Mortality by Urban Heat Islands in Hong Kong[J]. PloS one, 2012, 7(6): e38551.

[6] HKSAR. Hong Kong Planning Standards and Guidelines[EB/OL]. [201402]. http://www.pland.gov.hk/pland_en/tech_doc/hkpsg/.

[7] 任超, 吴恩融. 城市环境气候图一一可持续城市规划辅助信息系统工 具 [M]. 北京：中国建筑工业出版社, 2012 .

[8] 任超, 吴恩融, Katzschner Lutz, 等.城市环境气候图的发展及其应用
现状 [J]. 应用气象学报, 2012, 23(5): 593-603.

[9] HKSAR. Building Design to Foster a Quality and Sustainable Built Environment[EB/OL]. [2011-01]. http://www.bd.gov.hk/english/ documents/pnap/APP/APP151.pdf.

[10] HKSAR. Sustainable Building Design Guidelines[EB/OL]. [2011-01]. http://www.bd.gov.hk/english/documents/pnap/APP/APP152.pdf.

[11] Ng E, Yuan C, Chen L, et al. Improving the Wind Environment in High-density Cities by Understanding Urban Morphology and Surface Roughness: A Study in Hong Kong[J]. Landscape and Urban Planning, 2011, 101(1): 59-74.

[12] Landsberg H E. The Urban Climate[M]. Academic Press, 1981.

[13] Gago E J, Roldan J, Pacheco-Torres R, et al. The City and Urban Heat Islands: A Review of Strategies to Mitigate Adverse Effects [J]. Renewable and Sustainable Energy Reviews, 2013, 25: 749-758.

[14] Ng E. Air Ventilation Assessment System for High Density Planning and Design[C] // Proceedings of PLEA International Conference, 2006.

[15] Höppe P. The Physiological Equivalent Temperature: A Universal Index for the Biometeorological Assessment of the Thermal Environment[J]. International Journal of Biometeorology, 1999, 43(2): 71-75.

[16] Stathopoulos T, Wu H, Zacharias J. Outdoor Human Comfort in an Urban Climate[J]. Building and Environment, 2004, 39(3): 297-305.

[17] Cheng V, Ng E, Chan C, et al. Outdoor Thermal Comfort Study in a Sub-tropical Climate: A Longitudinal Study Based in Hong Kong[J]. International Journal of Biometeorology, 2012, 56(1): 43-56.

[18] Ng E, Cheng V. Urban Human Thermal Comfort in Hot and Humid Hong Kong[J]. Energy and Buildings, 2012, 55(10): 51-65.

[19] Cheng V, Ng E. Thermal Comfort in Urban Open Spaces for Hong Kong[J]. Architectural Science Review, 2006, 49(3): 236-242.

[20] Ng, E. Designing High-Density Cities: For Social and Environmental Sustainability[M]. Routledge, 2009.

[21] HKSAR. Hong Kong 2006 Population Census - Key Statistics[R/OL]. [2007-02]. http://www.statistics.gov.hk/pub/B11200372006XXXXB0100. pdf.

[22] 袁超. 缓解高密度城市热岛效应规划方法的探讨一以香港城市为例 [J]. 建筑学报, 2010(1): 120-123.

[23] Chen L, Ng E, An X, et al. Sky View Factor Analysis of Street Canyons and Its Implications for Daytime Intra-urban Air Temperature Differentials in High-rise, High-density Urban Areas of Hong Kong: A GIS-based Simulation Approach[J]. International Journal of Climatology, 2012, 32(1): 121-136.

[24] Svensson M K. Sky View Factor Analysis-Implications for Urban Air Temperature Differences[J]. Meteorological Applications, 2004, 11(3): 201-211.

[25] 史源, 任超, 吴恩融. 基于室外风环境与热舒适度的城市设计改进策 略——北京西单商业街为例 [J]. 城市规划学刊, 2012(5): 92-98.

(本文编辑：胡文娜) 